\title{
Deliberando ou protelando por justiça? Dinâmicas de remediação corporativa e resistência às vítimas pelas lentes do parentalismo: o caso da Fundação Renova no Brasil
}

\author{
RAJIV MAHER ${ }^{1}$ \\ ${ }^{1}$ Tecnológico de Monterrey / Egade Business School, San Pedro Garza García - México
}

\begin{abstract}
Resumo
Usando a lente da responsabilidade social corporativa política (RSCP) do parentalismo, investigamos neste artigo as dinâmicas e estratégias interacionais mais sutis e menos visíveis de poder, resistência e justificativa, que se manifestam entre uma fundação governada por vários stakeholders e as vítimas do colapso da barragem de uma empresa de mineração. Os dados foram coletados por meio de uma combinação de trabalho de campo e análise de arquivos para avaliar as percepções das vítimas, seus defensores e executivos da fundação. O campo revelou doze tensões dialéticas nas tentativas da Fundação Renova de reparar as injustiças causadas às vítimas. Neste trabalho, propomos um modelo de processo dialético de resistência e subversão das partes interessadas à RSCP parentalista, dado que, para se chegar a um acordo, o tempo foi usado estrategicamente em protelações que visavam exaurir as vítimas. Além disso, as organizações justificam seu parentalismo culpando os atrasos na burocracia e a responsabilidade compartilhada de múltiplas partes interessadas para qualquer deliberação. Por fim, defendemos que as vítimas devem ter paridade de voz na definição de sua reparação e que não cabe às empresas responsáveis por causar danos a decisão dessas questões.
\end{abstract}

Palavras-chave: RSC política. Parentalismo. Remediação corporativa de abusos de direitos humanos. protelação.

\section{Deliberating or stalling for justice? Dynamics of corporate remediation and victim resistance through the lens of parentalism: the case of the Renova Foundation in Brazil}

\begin{abstract}
Using the political corporate social responsibility (PCSR) lens of parentalism, this paper investigates the more subtle and less-visible interactional dynamics and strategies of power, resistance and justification that manifest between a multi-stakeholder-governed foundation and victims of a mining corporation's dam collapse. The Renova Foundation was established to provide remedy through a deliberative approach to hundreds of thousands of victims from Brazil's worst socio-environmental disaster - the collapse of Samarco Mining Corporation's Fundão tailings dam. Data were collected from a combination of fieldwork and archival analysis to assess the perceptions of victims, their defenders and foundation executives. The findings reveal 12 dialectical tensions from Renova's attempts to remedy the victim's injustices. The case analysis contributes through proposing a dialectical process model of stakeholder resistance and subversion to parentalist PCSR. The case reveals the pivotal use of time via the act of stalling as a strategic resource to exhaust victims and reach settlements. Furthermore, organizations justify their parentalism by blaming delays on the bureaucracy and shared responsibility of multi-stakeholder deliberation. Ultimately, I contend that victims must have an equal voice in the outcome of their remediation and that businesses responsible for causing harm should not decide these matters.
\end{abstract}

Keywords: Political CSR. Parentalism. Corporate remediation of human rights abuses. Stalling.

\section{¿Deliberar o posponer en pos de justicia? Dinámica de la remediación empresarial y la resistencia de las vícti- mas a través de la lente del parentalismo: el caso de la Fundação Renova en Brasil}

\section{Resumen}

Utilizando la lente de la responsabilidad social corporativa política (PCSR) del parentalismo, este documento investiga las dinámicas y estrategias interaccionales más sutiles y menos visibles de poder, resistencia y justificación que se manifiestan entre una fundación gobernada por múltiples partes interesadas y las víctimas de la ruptura de una represa de relaves. La Fundação Renova se estableció para brindar reparación mediante un enfoque deliberativo a cientos de miles de víctimas del peor desastre socioambiental de Brasil: el colapso de la represa Fundão, de propiedad de Samarco Mineração. Los datos se recopilaron a partir de una combinación de trabajo de campo y análisis de archivos para evaluar las percepciones de las víctimas, sus defensores y ejecutivos de la fundación. Los hallazgos revelan 12 tensiones dialécticas en los intentos de Renova de remediar las injusticias a las víctimas. El análisis de caso contribuye proponiendo un modelo de proceso dialéctico de resistencia y subversión de los interesados a la PCSR parentalista. El caso revela el uso del tiempo como recurso estratégico, con demoras destinadas a agotar a las víctimas y llegar a acuerdos. Además, las organizaciones justifican su parentalismo atribuyendo los retrasos a la burocracia y a la responsabilidad compartida de múltiples partes interesadas para cualquier deliberación. Finalmente, sostenemos que las víctimas deben tener paridad de voz en la definición de su reparación y que la decisión de esas cuestiones no les compete a las empresas responsables de causar daños.

Palabras clave: RSE Política. Parentalismo. Reparación empresarial de abusos de derechos humanos. Posponer.

Artigo originalmente publicado em: Maher, R. (2021). Deliberating or Stalling for Justice? Dynamics of Corporate Remediation and Victim Resistance Through the Lens of Parentalism: The Fundão dam Collapse and the Renova Foundation in Brazil. Journal of Business Ethics. Recuperado de https://doi.org/10.1007/s10551-021-04803-6

Artigo convidado submetido em 27 de maio de 2021 e aceito para publicação em 22 de junho de 2021.

DOI: http://dx.doi.org/10.1590/1679-395120210110 


\section{INTRODUÇÃO}

Em novembro de 2015, a barragem de rejeitos de Fundão, de propriedade da Samarco (uma joint venture entre a angloaustraliana BHP e a brasileira Vale), desabou em Mariana, Brasil, provocando a pior catástrofe ambiental da história do país. O desastre ceifou a vida de 19 pessoas e destruiu as casas e os meios de subsistência de aproximadamente 3 milhões de pessoas. Em linha com a Responsabilidade Social Corporativa Política (RSCP) e os Princípios Orientadores das Nações Unidas para Empresas e Direitos Humanos (UNGP), a Samarco adotou uma abordagem intensiva de diálogo com as vítimas. Assim, sete meses depois, com o apoio do Estado brasileiro (embora sem consulta prévia às vítimas ou aos seus familiares), a Samarco decidiu criar e financiar integralmente a Fundação Renova, cujo objetivo seria administrar soluções justas, de forma transparente e respeitosa com os direitos humanos, de tal forma que "[...] nenhuma parte envolvida tenha controle sobre a decisão" (Fundação Renova, 2020). Esta organização, fundada sobre os princípios fundamentais da democracia deliberativa, é uma complexa estrutura de governança, composta por 70 entidades representantes da sociedade civil, autoridades públicas e academia.

Por definição, RSCP é um modelo estendido de governança, no qual as empresas desempenham um papel ativo na regulamentação democrática, contribuindo para a regulamentação global e fornecendo bens públicos (Scherer \& Palazzo, 2011), alinhando-se, assim, ao conceito habermasiano de democracia deliberativa para obter legitimidade social (Mena \& Palazzo, 2012). Já a democracia deliberativa, conceituada dentro do Political CSR (PCSR), permite-nos "[...] reconhecer a contribuição de atores estatais e não estatais para a governança global, tanto nos processos tradicionais institucionalizados quanto nos processos de deliberação pública, que emergem fora do reino tradicional da política institucionalizada" (Scherer \& Palazzo, 2011, p. 918).

A democracia deliberativa incentiva a participação e o diálogo por meio de iniciativas multi-stakeholders (sigla em inglês: MSIs - multi-stakeholder initiatives), mecanismos de quase-direito (soft laws ou droit mou; ou seja, regras cujo valor normativo é limitado e não são juridicamente obrigatórias), das quais participam empresas e organizações da sociedade civil, que visam preencher a lacuna deixada pelos governos na abordagem das externalidades socioambientais causadas por empresas (Mena \& Palazzo, 2011). No limite, é apontado o meio ideal para alcançar o consenso entre as partes em disputa, já que se vale de diálogo intensivo, participação e engajamento entre atores empresariais e vítimas, para obter justiça em resposta aos abusos dos direitos humanos corporativos (Schormair \& Gerlach, 2020).

Entretanto, há ceticismo quanto à eficácia da democracia deliberativa, devido ao interesse próprio das corporações, ao desiquilíbrio de poder econômico-político entre elas e as partes interessadas (Alamgir \& Banerjee, 2019; Brand, Blok \& Verweij, 2019; Maher, 2019). Fundamentalmente, as empresas podem explorar as Iniciativas Multi Atorais (IMAs) para legitimar seus atos de irresponsabilidade e solidificar suas posições em cenários de conflito (Moog, Spicer \& Böhm, 2015). Assim, nestes espaços de MSI restringe-se a deliberação política real, visto que vozes minoritárias e radicais são frequentemente (auto) excluídas (Ehrnström-Fuentes, 2016; Maher, 2019).

Este estudo tem como objetivo analisar a micropolítica e as tensões que cercam a Fundação Renova e as vítimas do rompimento da barragem de Fundão, propondo um modelo de processo dialético de como as organizações, por meio da deliberação, implementam estratégias parentalistas de RSCP e como as partes interessadas são capazes de resistir a elas. Aqui, entende-se por parentalismo a metáfora proposta por Etchanchu e Djelic (2019), a qual equipara o comportamento das organizações ao de um pai liberal moderno com seus filhos (no caso, as partes interessadas); ou seja, elas os convidam para o diálogo (semelhante à deliberação), conferem-Ihes alguma autonomia, enquanto ainda se apegam ao poder de tomada de decisão para controlar os resultados dessa pseudo-negociação. A rigor, a pergunta de pesquisa ficou assim formulada: em que medida examinar, pelas lentes do parentalismo, o processo de recompensação das vítimas da barragem pela Fundação Renova desvela as tensões e estratégias mais sutis e dialéticas de poder, influência, justificativas e resistência das vítimas?

Para respondê-la, realizamos três rodadas de trabalho de campo na cidade de Mariana, entre janeiro de 2019 e janeiro de 2020. Foram conduzidas 69 entrevistas semiestruturadas, remotas e pessoalmente, com múltiplos participantes do município. Testemunhos adicionais também foram analisados por meio de imagens de vídeo. Posteriormente, os dados foram codificados de acordo com as características do parentalismo deliberativo (compreendendo cuidado igualitário, controle de resultados, prática de convocação, poder de manipulação e falta de conhecimento e justificativa de recursos da 'criança') (Etchanchu \& Djelic, 2019), e, ao mesmo tempo, abrangem [os dados] frequentes discussões com atingidos, ativistas e promotores". 

no Brasil

Este artigo aborda contribuições e reflexões para a academia e a sociedade em geral. No caso da primeira, contribui com o avanço da discussão sobre os desafios embutidos na mudança da teoria liberal para a deliberativa (Scherer \& Palazzo, 2011), examinando um caso empírico de democracia deliberativa, no qual as vítimas foram obrigados a participar, em busca de justiça por terem sido vítimas da irresponsabilidade corporativa. Outra contribuição está em evidenciar formas menos visíveis de poder, instrumentalizadas por empresas em instâncias de democracia deliberativa, como em casos de engajamento de múltiplas partes interessadas, as quais têm sido subestimadas (Gond, Barin Cruz, Raufflet \& Charron, 2016). Assim, ao se estudar RSCP, devemos considerar o tempo como instrumento de práticas maquiavélicas, tática de encenação e paralisação, o que até aqui foi negligenciado. No caso da sociedade, cabe refletir sobre o fato de que as organizações retêm o poder e manipulam as partes envolvidas, encenando uma participação efetiva, que engendra a capacidade de explorar o tempo como um recurso de paralisar as dinâmicas de remediação corporativa e resistir às vítimas.

Este artigo está dividido em seis seções, além desta introdução. Na próxima, revisitamos a literatura sobre democracia deliberativa, RSCP, parentalismo e remediação corporativa. Na terceira, apresentamos o caso de Mariana. Posteriormente, descrevemos nosso percurso metodológico. Na quinta, relatamos os resultados de nossa pesquisa de campo, os quais são discutidos à luz do marco teórico. Na última, apresentamos uma conclusão e propomos novas agendas de pesquisa.

\section{DEMOCRACIA DELIBERATIVA E MSIS}

As iniciativas de governança privada têm proliferado desde o final do século XIX com base nas políticas neoliberais (Vogel, 2010); todavia, os estudos de RSCP têm privilegiado o conceito habermasiano de democracia deliberativa como instrumento de legitimidade para a governança privada, como atores políticos na economia globalizada moderna (Sabadoz \& Singer, 2017). Segundo Habermas (2000), o diálogo deve ter como objetivo o entendimento mútuo de uma situação e servir de trampolim para a ação coletiva. Dentro das instâncias de diálogo, Habermas (1998) identifica quatro características cruciais: (i) ninguém com uma contribuição relevante deve ser excluído; (ii) todos os participantes têm a mesma oportunidade de fazer contribuições; (iii) os participantes não devem enganar e devem ser sinceros no que dizem; e (iv) a comunicação deve ser livre de coerção externa e interna (Habermas, 1998). Sem “[...] (iii) engano e (iv) coerção, nada além de um argumento sólido deve inclinar a balança a favor da aceitação de uma norma controversa” (Habermas, 1998, p. 44).

Nesta mesma linha, as pesquisas em PCSR enfatizam a importância do diálogo dentro da abordagem deliberativa, "[...] com o pressuposto de que a legitimidade de uma decisão política repousa na qualidade discursiva do processo de tomada de decisão" (Scherer \& Palazzo, 2007, p. 1107). A democracia deliberativa, baseada no diálogo e no consenso, visa garantir a legitimidade das deliberações finais para todas as partes interessadas, por meio de um argumento aberto, livre de manipulação por atores mais poderosos (Bäckstrand, 2010).

Idealmente, as abordagens democráticas envolvem ONGs ou movimentos sociais que representam os cidadãos, ressaltando-se que as primeiras engajam-se com empresas para enfrentar os desafios políticos relacionados à RSC de uma maneira mais legítima (Mena \& Palazzo, 2012). As MSIs são um exemplo de arranjo de governança popular em que a democracia deliberativa pode florescer, visando a se alcançar um consenso em relação a temas socioambientais (Mena \& Palazzo, 2012).

A legitimidade democrática das MSIs compreende a legitimidade de entrada (inclusão, justiça processual, orientação consensual e transparência) e a legitimidade de saída (cobertura de regras, eficácia e cumprimento) (Mena \& Palazzo, 2012).

Já os princípios deliberativos de participação, engajamento e diálogo entre culpados e vítimas corporativos também são promovidos como ideais para restaurar a justiça (Schormair \& Gerlach, 2019). Todavia o modelo de remediação corporativa, proposto por estes autores, não se aplica a casos de abusos de direitos humanos em grande escala.

\section{Boa educação para superar as deficiências das MSIs}

Os estudos sobre PCSR negligenciam as restrições que emanam dos desequilíbrios de poder político e econômico das MSIs, ou seja, as empresas podem aproveitar tais restrições para mascarar seu comportamento irresponsável (greenwashing) e recuperar a legitimidade perdida (Moog et al., 2015). 

no Brasil

Tanto PCSR como MSIs foram objeto de questionamento por sua insensibilidade em relação aos impactos sobre as partes interessadas marginalizadas (Alamgir \& Banerjee, 2019; Ehrnström-Fuentes, 2016; Maher, 2019). De acordo com essas críticas, a pesquisa sobre o modelo deliberativo de PCSR falha em problematizar a noção de poder no envolvimento das partes interessadas (Dawkins, 2015) e, de forma mais geral, na democracia deliberativa dentro das MSIs (Fougère \& Solitander, 2019). Ademais, os espaços da MSI podem restringir a deliberação política genuína, sufocando vozes minoritárias e radicais que frequentemente se (auto) excluem (Ehrnström-Fuentes, 2016; Maher, 2019).

Já a democracia deliberativa não pode lidar com as realidades confusas da política cotidiana por causa de pressupostos idealistas de atores racionais participantes (Brand et al., 2019). A rigor, a obsessão em alcançar consenso por meio da deliberação obscurece os processos de dominação e não permite espaços de diferença e coexistência (Banerjee, 2018). De fato, a proposta de consenso pelos proponentes de PCSR e MSIs é contestada por excluir a dimensão dos conflitos, sob a ótica do pluralismo agnóstico (Arenas, Albareda \& Goodman, 2020; Brand et al., 2019), que contempla emoções, políticas, subjetividades e contestação, a fim de resistir à obrigação de alcançar acordos racionais por meio de processos deliberativos técnicos e desapaixonados. Por exemplo, Arenas et al. (2020, p. 33) encorajaram "[...] diferentes participantes discutindo, questionando, desafiando suas preocupações sobre procedimentos, inclusão, transparência, estruturas, impactos das decisões", para que os fóruns deliberativos de MSIs prosperem.

Embora haja deficiências significativas das MSIs no cumprimento das promessas do PCSR, muito pouco foi relatado sobre os mecanismos mais suaves e menos visíveis de disparidades de poder que visam à legitimidade deste (Gond et al., 2016). No bojo dessa discussão, Etchanchu e Djelic (2019) conceberam a noção de "parentalismo", conceituada como uma versão moderna de controle que reflete valores liberais e progressivos sem gênero (Etchanchu \& Djelic, 2019).

O parentalismo tenta reconciliar duas dimensões aparentemente opostas, de um lado, poder e controle (tradicionalmente masculino), de outro, benevolência, nutrição e cuidado (tradicionalmente feminino) (Etchanchu \& Djelic, 2019). Assim, este conceito infere uma tensão subjacente na decisão sobre a autonomia e os melhores interesses de uma criança. Ao contrário do paternalismo, em que a figura do pai exerce mais autoridade e 'sempre unilateralmente sabe o que é melhor para a criança", o parentalismo defende as características maternas tradicionais de benevolência, cuidado e nutrição em igual medida, enquanto simultaneamente influência e controla a tomada de decisão da criança por meio de uma aparente conversa franca (Etchanchu \& Djelic, 2019).

Para os fins deste artigo, concentramo-nos no 'paternalismo deliberativo', cujas principais características são apresentadas no Quadro 1.

Quadro 1

Principais características das dimensões do parentalismo

\begin{tabular}{|c|c|}
\hline Dimensão do parentalismo & Características \\
\hline Cuidado & Igualitário \\
\hline Controle & Controle parental de decisão \\
\hline Prática & Convocação por meio de participação formal e não substantiva \\
\hline Poder & Manipulativo - definindo a agenda \\
\hline Justificativa & Falta de conhecimento parental e experiência \\
\hline
\end{tabular}

Fonte: Adaptado de Etchanchu e Djelic (2019).

Apesar de revelarem as tensões dialéticas de antagonismo estruturado na 'face de carvão' da deliberação de RSC entre multinacionais e fornecedores, Reinecke e Donaghey (2021) afirmam que as corporações ainda desempenham um papel fundamental na facilitação do diálogo entre gerentes e trabalhadores. Os processos de diálogo entre as multinacionais e os trabalhadores nas fábricas de Bangladesh representam "[...] um passo importante para (re)conceituar os beneficiários da RSE em nível local como participantes ativos com agência, voz e controle em processos deliberativos, em vez de recipientes passivos" (Reinecke \& Donaghey, 2021, p. 20). Assim, o parentalismo pode ser cuidadosamente evitado pelas empresas, desde que garantam o poder de decisão de suas partes envolvidas. 

no Brasil

Uma limitação da estrutura de parentalismo, conforme reconhecido por Etchanchu e Djelic (2019), é a sua 'centralização nos pais'. Ou seja, coloca muita ênfase nos pensamentos e sentimentos das empresas-mãe, sem considerar como as partes interessadas tendem a reagir. Além de destacar e avaliar como as organizações parentais implementam estratégias de retenção de poder destinadas a angariar a aceitação das partes interessadas, abordamos ainda neste artigo como estas últimas reagem e o que lhes permite resistir ao parentalismo, bem como buscamos compreender as justificativas morais organizacionais que surgem em resposta a tal resistência. Isso permite o desenterramento de processos dialéticos e dinâmicas que moldam a dinâmica deliberativa em contextos de MSI.

\section{CONTEXTUALIZANDO A MINERADORA SAMARCO E MARIANA}

O desastre da barragem de Fundão foi amplamente coberto pela academia brasileira, incluindo a discussão sobre a desterritorialização a que o desastre levou, com centenas de famílias perdendo suas casas e assentamentos e os impactos culturais incomensuráveis sofridos pelas vítimas (Miranda, Friede, Rodrigues \& Almeida, 2017). De um ângulo mais político, houve críticas ao setor de mineração no Brasil, ao apoio que recebe do governo e à hipervalorização dos direitos corporativos sobre os humanos (Zhouri, Oliveira, Zucarelli \& Vasconcelos, 2018). Esses autores destacaram as fissuras no manejo do processo de remediação liderado pelas corporações e os impactos sociais negativos, incluindo o esgotamento físico e psíquico dos que lutam por justiça.

\section{PERCURSO METODOLÓGICO}

Para abordar as questões de pesquisa relacionadas a como as partes interessadas reagem ao parentalismo organizacional e como as organizações justificam seu parentalismo, tem-se como base uma abordagem abdutiva (Dubois \& Gadde, 2002), a qual é útil quando os pesquisadores buscam descobrir novos conceitos e relações e avançar nas teorias existentes (Dubois \& Gadde, 2002, p. 560).

Os dados foram coletados em trabalho de campo e extensa análise de arquivos de vídeos e documentos. Três viagens de campo a Mariana desde o início de 2019 resultaram em 48 dias de conteúdo para análise. Antes disso, a primeira visita de pesquisa a Mariana ocorreu em dezembro de 2012, quando foram realizadas 18 entrevistas quase três anos antes do desastre, enquanto as percepções da comunidade sobre a mineração eram pesquisadas. Durante a primeira visita, evidenciou-se que a comunidade era altamente dependente da Samarco para seu sustento e economia em geral. Esta visita permitiu uma familiarização significativa com o contexto cultural local e contatos importantes para futuras pesquisas de campo seis anos depois, facilitando assim o acesso a mais entrevistados em meados de 2016 e durante as visitas subsequentes em janeiro, agosto e dezembro de 2019 e em janeiro de 2020. Desde meados de 2016, tem-se mantido contato com uma líder atingida, de Bento Rodrigues, que foi entrevistada e a quem se solicitou um depoimento em vídeo durante uma conferência sobre defensores dos direitos humanos. Desde então, têm sido analisados documentos de arquivo, bem como vídeos, reportagens da mídia e publicações acadêmicas brasileiras sobre o desastre. O Quadro 2 ilustra o cronograma com os principais eventos desde novembro de 2015, quando ocorreu o rompimento da barragem, até fevereiro de 2020.

No total, foram conduzidas 69 entrevistas semiestruturadas e informais. No interesse de organizar os dados, foram agrupadas todas as trocas de áudio com cada entrevistado em uma única entrevista. Entre os entrevistados, tem-se representantes da sociedade civil, vítimas, autoridades locais, psicólogo de atingidos, Ministério Público estadual e federal, a Fundação Renova, representantes de igrejas e comércio local. As entrevistas apresentam duração de 20 a 180 minutos (algumas das mais longas ocorreram em conversas durante o jantar, caminhadas ou em trânsito durante uma estada de dois dias em uma fazenda em Paracatu, a convite de seus proprietários - uma família atingida - em dezembro de 2019). Durante uma visita em agosto de 2019, participamos também de um encontro comunitário, no qual foi possível apresentar a pesquisa a um grupo focal. A versão final aceita deste documento teve apresentação online na reunião quinzenal da Comissão de Atingidos em Mariana, no início de abril de 2021. Os participantes confirmaram que o documento resume com precisão a situação que eles estão tendo de suportar. 0 único comentário referiu-se ao fato de as estratégias (encenar, protelar e justificar) postas em prática pela Renova estarem ainda mais acentuadas, com a pandemia sendo usada como uma nova desculpa. 

no Brasil

Foram analisadas mais de 15 horas de vídeo de quatro assembleias, que incluíram depoimentos de atingidos, ativistas, promotores, políticos e executivos da Renova, bem como reportagens da imprensa e da mídia, incluindo dois jornais administrados por atingidos e pela Fundação Renova, nos quais encontram-se relatos em primeira mão sobre a vida das vítimas após o desastre.

As perguntas típicas feitas durante as entrevistas basearam-se nas percepções e experiências vividas por indivíduos que participaram dos espaços de democracia deliberativa da Renova, em particular para avaliar o nível de eficácia que esses espaços de diálogo tinham em termos de remediação satisfatória. Também foi objeto de questionamento a percepção dos entrevistados quanto à abordagem da Fundação Renova sobre remediação. Essas respostas foram comparadas com o modelo de Governança Multi Atoral ou (Multistakeholder Governance em inglês) (MSG) dialógico, inclusivo e robusto, que é comunicado pela fundação. Em geral, muitas vezes se pediu aos entrevistados que elaborassem suas visões sobre o processo de reparação e o papel desempenhado pelo diálogo neste espaço. Em virtude da complexidade desse processo e do modelo MSG da Fundação Renova, das queixas expressas pelas vítimas e das muitas instâncias de diálogo em que os entrevistados participaram, as entrevistas geralmente duravam mais de uma hora e eram guiadas por algumas perguntas abertas e acompanhadas por múltiplas consultas (incluindo comunicações eletrônicas pós-entrevista).

Os dados (transcrições de entrevistas, observações de campo e vídeos de depoimentos em relação à fundação) foram revisados várias vezes e sua análise teve como base as categorias a priori de tipologia de parentalismo (cuidado, controle, prática, poder e justificativa), bem como uma categoria emergente (resistência), resultado do trabalho de codificação aberta.

\section{Quadro 2}

\section{Cronograma dos principais eventos}

\begin{tabular}{|c|c|}
\hline Data & Evento \\
\hline Novembro de 2015 & $\begin{array}{l}\text { Ruptura da barragem do Fundão: } 19 \text { pessoas morrem. Quase } 300 \text { famílias perdem suas casas } \\
\text { na zona rural e são temporariamente reassentadas no principal centro urbano de Mariana. }\end{array}$ \\
\hline Dezembro de 2015 & Ministério Público do Estado entra com ação civil pública contra a Samarco. \\
\hline $\begin{array}{l}\text { Novembro de } 2015 \text { - } \\
\text { Julho de } 2016\end{array}$ & Reuniões frequentes e audiências entre Samarco e atingidos. \\
\hline Março de 2016 & $\begin{array}{l}\text { Termo de Transação e Ajustamento de Conduta (TTAC) firmado entre a Samarco e funcionários } \\
\text { do Estado (sem inclusão de vítimas ou Ministério Público) e criação da Fundação Renova. }\end{array}$ \\
\hline Maio de 2016 & $\begin{array}{l}\text { Os atingidos de Bento Rodrigues votaram e decidiram sobre a localização da sua nova } \\
\text { aldeia. A Renova prometia a conclusão de novas aldeias e casas em } 2018 \text { e depois em } 2019 . \\
\text { Permanecem incompletas no final de } 2020 .\end{array}$ \\
\hline Agosto de 2016 & Fundação Renova entra em operação e Samarco sai da comunidade. \\
\hline Janeiro de 2018 & $\begin{array}{l}\text { Atingidos conquistam na Justiça o direito de receber assistência técnica da ONG Cáritas } \\
\text { (financiada indiretamente pela Renova). }\end{array}$ \\
\hline Agosto de 2018 & $\begin{array}{l}\text { Assinado o TAC (Termo de Ajustamento de Conduta) - Governança, elevando o papel do } \\
\text { atingido a participante no processo de remediação. Isso inclui a criação e o financiamento } \\
\text { de comissões locais em nível municipal. }\end{array}$ \\
\hline Fevereiro de 2020 & $\begin{array}{l}\text { O tribunal decide a favor de os atingidos usarem sua própria 'matriz de perdas' para pedidos } \\
\text { de indenização à Fundação Renova. A fundação apelou imediatamente da decisão. }\end{array}$ \\
\hline
\end{tabular}

Fonte: Elaborado pelo autor.

\section{Contexto do caso}

A mineradora Samarco é especializada na extração de minério de ferro e foi criada em 1977 com a participação da gigante mineradora brasileira Vale e da anglo-australiana BHP Billiton. O rompimento da barragem de Fundão, em 2015, é descrito como o pior desastre ambiental da história do Brasil. Pouco mais de três anos depois, em janeiro de 2019, a coproprietária da Samarco, a barragem de rejeitos da Vale Feijão, localizada a pouco mais de $50 \mathrm{~km}$ de distância, também se rompeu, desta vez matando 270 pessoas; mineiros, em sua maioria. O desastre da barragem de Fundão ocorreu em 5 de novembro de 2015, em Bento Rodrigues, uma vila colonial localizada no município de Mariana, Brasil. Apenas uma hora após o colapso, 35 bilhões de toneladas de resíduos de minério de ferro e lama engolfaram e destruíram a vila próxima. A devastação continuou ao longo 
dos próximos $670 \mathrm{~km}$, varrendo tudo em seu caminho por 42 municípios até chegar à costa do Oceano Atlântico. 0 desastre ceifou a vida de 19 pessoas e afetou negativamente 23.000 outras famílias (Reuters, 2018), podendo ter prejudicado até 3 milhões de pessoas, de acordo com um recente comunicado da ONU.

Imediatamente após o rompimento da barragem, quase 400 famílias, a maioria de Bento Rodrigues (localizada a $25 \mathrm{~km}$ da cidade de Mariana), ficaram desabrigadas, suas casas e bens foram varridos ou destruídos pelo deslizamento causado pela barragem. Em resposta, a Samarco proveu acomodação temporária, principalmente em hotéis, às famílias atingidas e também fez pagamentos emergenciais a cada uma delas para que fossem usados nos supermercados locais.

Na seção seguinte, serão abordados os três primeiros aspectos da estrutura relativos a cuidado, controle e prática.

\section{ANÁLISE DOS DADOS}

\section{Tensões dialéticas com a Fundação Renova: cuidado, controle e prática}

A Fundação Renova, criada em março de 2016, com um orçamento de $\mathrm{R} \$ 11,6$ bilhões, foi constituída com base em um TTAC, tendo como único objetivo remediar os danos causados pelo rompimento da barragem de Fundão. O TTAC define e rege o escopo do trabalho e das operações da Renova.

Nos primeiros nove meses após o desastre, a Samarco ficou responsável pelas reuniões de consulta com os atingidos, que abordaram o processo de remediação, compartilhamento de informações, reassentamento e outras questões antes de a Fundação Renova entrar em operação em agosto de 2016.

A Figura 1 revela a estrutura organizacional da Fundação Renova para reparação a vítimas, englobando outros conselhos e comitês que deliberam e acompanham o modelo de governança. Seu modelo de grupo com múltiplos stakeholders compreende mais de 70 organizações, incluindo 40 ONGs e 25 universidades. A Renova conta ainda com 7.000 associados, diretos ou indiretos.

\section{Figura 1}

\section{Modelo de governança da Fundação Renova}

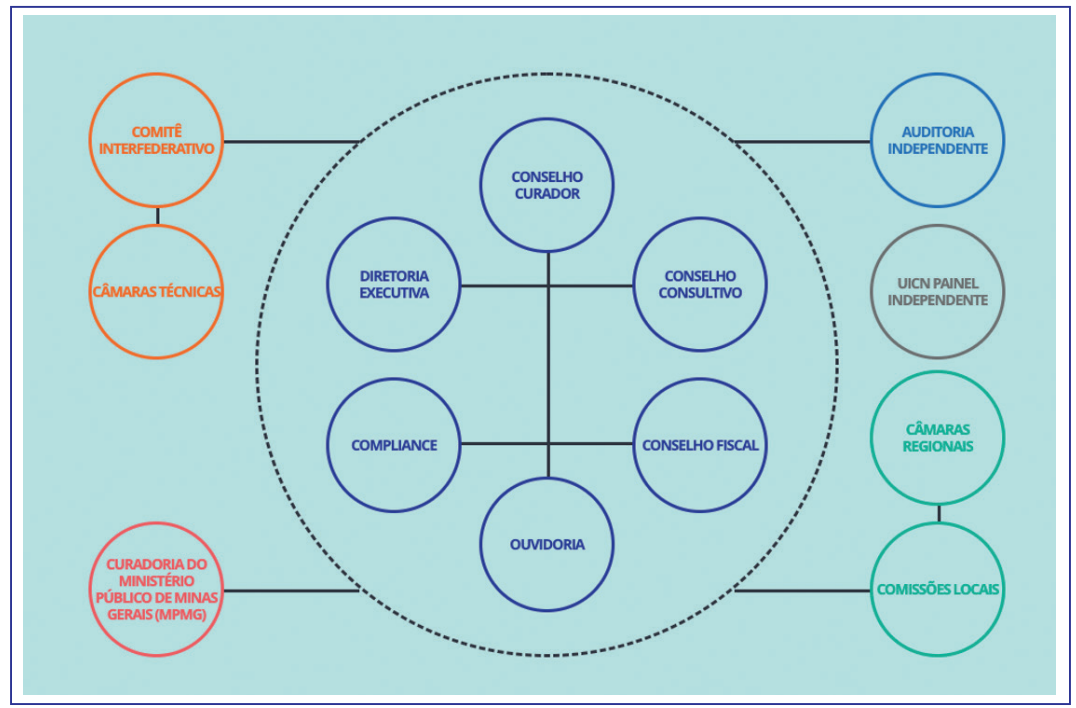

Fonte: Fundação Renova (2020).

Vale ressaltar que a Fundação Renova não foi anunciada até março de 2016. É aqui que se observa o surgimento da primeira tensão dialética, visto que, apesar das sessões de consulta intensiva ('cuidados' parentais) com as vítimas, os atingidos não tiveram qualquer envolvimento na concepção ou desenho da fundação. A notícia da criação da fundação surpreendeu os atingidos e a sociedade civil, conforme foi levantado durante as entrevistas com esses atores, que não haviam sido consultados 

resistência às vítimas pelas lentes do parentalismo: o caso da Fundação Renova no Brasil

sobre a ideia de uma fundação operando como uma MSI que se encarregaria de sua reparação: "Vale lembrar que a fundação não foi criada ou desenhada com a entrada dos atingidos, ela foi inventada nos cantos escuros do Congresso de Brasília entre políticos e mineradoras. Tarde demais para ter a participação de todos depois!" (Entrevista com a Procuradoria Estadual de Mariana, 2019).

O Quadro 3 oferece uma síntese relativa às doze tensões dialéticas que confundem as estratégias parentais da Renova, com citações ou dados de apoio.

\section{Quadro 3}

Tensões dialéticas e as dimensões do parentalismo

\begin{tabular}{|c|c|c|}
\hline Tensão dialética & $\begin{array}{l}\text { Dimensão do } \\
\text { parentalismo }\end{array}$ & Citação ou explicação ilustrativa \\
\hline $\begin{array}{l}\text { Encenação: consultas intensas e } \\
\text { longas com as vítimas, mas nenhum } \\
\text { envolvimento das vítimas na criação } \\
\text { ou projeto da fundação. }\end{array}$ & Cuidado & $\begin{array}{l}\text { "Não, eu não me lembro de nunca, nem uma vez, durante essas exaustivas reuniões } \\
\text { intermináveis que a Samarco mencionou a ideia de criar uma base para nossa } \\
\text { compensação, descobrimos através da mídia como todo mundo" (Entrevista com } \\
\text { uma jovem vítima, via aplicativo de mensagens, 2020). }\end{array}$ \\
\hline $\begin{array}{l}\text { Encenação: a Fundação afirma ser } \\
\text { independente, mas é totalmente } \\
\text { financiada por ambas as corporações } \\
\text { de mineração. }\end{array}$ & Controle & $\begin{array}{l}\text { “Fundação Renova é uma colônia de empresas que não tem autonomia e é controlada } \\
\text { pelas empresas" (Entrevista com a Procuradora do Estado, 2019). }\end{array}$ \\
\hline $\begin{array}{l}\text { Encenação: 'árvore venenosa', em } \\
\text { que todo o poder de decisão cabe } \\
\text { ao Conselho de Governadores (que } \\
\text { é dominado por representantes de } \\
\text { empresas de mineração). }\end{array}$ & Controle & $\begin{array}{l}\text { "A Renova e as empresas estão jogando contra nós porque nenhuma decisão } \\
\text { importante pode ser tomada até que o Conselho de Governadores concorde, que } \\
\text { é dominado pelas empresas, apesar das muitas instâncias de deliberação em que } \\
\text { nada pode efetivamente ser feito sem que o Conselho de Governadores liberasse } \\
\text { os recursos" (Entrevista com o Ministério Público Federal, 2020). }\end{array}$ \\
\hline $\begin{array}{l}\text { Encenação: processo de mediação } \\
\text { imparcial (PIM) para compensação } \\
\text { extrajudicial, no qual as vítimas } \\
\text { renunciam ao seu direito a recursos } \\
\text { legais futuros. }\end{array}$ & Controle & $\begin{array}{l}\text { "Se você se aproximar de qualquer atingido três anos depois e dizer-Ihes: 'Ei, olha, eu } \\
\text { tenho (uma falsa) compensação para você, basta assinar e tudo pode acabar com um } \\
\text { termo de quitação', o atingido aceita porque ele não aguenta mais. As pessoas não } \\
\text { têm energia para ir às reuniões porque estão exaustas. Essa estratégia corporativa } \\
\text { funciona" (Representante da Cáritas no III UFMG Debate, CAC UFMG, 2019). }\end{array}$ \\
\hline $\begin{array}{l}\text { Cooptar e silenciar ONGs e academia } \\
\text { por meio de acordos de não divulgação } \\
\text { durante a colaboração. }\end{array}$ & Controle & $\begin{array}{l}\text { Diferentes acadêmicos e ONGs brasileiras não puderam colaborar ou comentar a } \\
\text { presente pesquisa por causa de sua relação de trabalho anterior ou atual com } \\
\text { a Renova. }\end{array}$ \\
\hline $\begin{array}{l}\text { Protelando: dando volta nas vítimas } \\
\text { em vez de responder suas perguntas } \\
\text { diretamente ou cumprir promessas. }\end{array}$ & $\begin{array}{l}\text { Prática e } \\
\text { poder }\end{array}$ & $\begin{array}{l}\text { "Os atrasos são usados estrategicamente pelas empresas para cansar as vítimas, } \\
\text { para desistir de seus direitos, o que, em grande parte, é vencedor" (Representante } \\
\text { da Cáritas no III UFMG Debate, CAC UFMG, 2019). }\end{array}$ \\
\hline $\begin{array}{l}\text { Encenação: representando indeniza- } \\
\text { ções e compensações como benefí- } \\
\text { cios e não como conformidade legal. }\end{array}$ & $\begin{array}{l}\text { Prática e } \\
\text { poder }\end{array}$ & $\begin{array}{l}\text { "Para a Renova, as vítimas, ou atingidos, são referidas como 'pessoas impactadas', } \\
\text { o termo atingido é mais grave e 'impactado' pode significar vítimas indiretas; dessa } \\
\text { forma, minimizam a gravidade da situação. Eles chamam o 'crime' de 'acidente' - } \\
\text { um crime é premeditado, um acidente é algo como um furacão. Renova fala de } \\
\text { benefícios em vez de direitos, benefícios em português significa mais uma doação, } \\
\text { mas essa luta é por direitos" (Entrevista com a promotora de Justiça do Estado, 2019). }\end{array}$ \\
\hline $\begin{array}{l}\text { Conhecimento e assimetrias de poder } \\
\text { emocional. }\end{array}$ & $\begin{array}{l}\text { Controle, } \\
\text { prática e } \\
\text { poder }\end{array}$ & $\begin{array}{l}\text { "Como um atingido pode ir e participar se eles não têm informações ou levar alguém } \\
\text { em quem confiam para acompanhá-los às reuniões? As pessoas não recebem nada } \\
\text { há mais de quatro anos. Como posso participar de uma negociação quando estou } \\
\text { com fome e desempregado? [...] Então, como você pode colocar as pessoas com } \\
\text { relações de poder desiguais para sentar e negociar?" (Entrevista com uma ativista } \\
\text { feminina do Movimento dos Afetados por Barragens [MAB], 2019). }\end{array}$ \\
\hline $\begin{array}{l}\text { Autocontradição ao decidir por } \\
\text { fundação como opção "menos pior" } \\
\text { quanto a eficiência. }\end{array}$ & Justificação & $\begin{array}{l}\text { "Como explicado no início de uma entrevista pelo diretor de Assuntos Institucionais } \\
\text { da Renova, há casos de danos ambientais ainda no tribunal } 31 \text { anos depois. Quando o } \\
\text { Estado lidera na busca de compensação por danos ambientais, há muita ineficiência. } \\
\text { Portanto a ideia de uma fundação independente é melhor (ou a 'menos pior'). No } \\
\text { entanto, pouco depois, discutimos como é difícil para a fundação evitar atrasos } \\
\text { na prestação de indenizações e compensações" (Nota de entrevista do Diretor de } \\
\text { Assuntos Institucionais da Renova, 2019). }\end{array}$ \\
\hline
\end{tabular}




\begin{tabular}{|c|c|c|}
\hline Tensão dialética & $\begin{array}{l}\text { Dimensão do } \\
\text { parentalismo }\end{array}$ & Citação ou explicação ilustrativa \\
\hline $\begin{array}{l}\text { A culpa da Fundação pelo modelo } \\
\text { MSG: busca de consenso como barreira } \\
\text { à remediação eficiente. }\end{array}$ & Justificação & $\begin{array}{l}\text { "É importante notar que a FR culpa os atrasos no diálogo e que inverte a lógica... } \\
\text { diálogo requer ação e sem isso você perde a confiança... culpam o diálogo, o } \\
\text { engajamento e a participação com os atingidos para justificar os atrasos que } \\
\text { invertem a lógica para fins de diálogo" (Entrevista com a gerente da Cáritas, 2020). }\end{array}$ \\
\hline $\begin{array}{l}\text { A culpa da Fundação pelo modelo MSG } \\
\text { de responsabilidade compartilhada } \\
\text { em quaisquer decisões. }\end{array}$ & Justificação & $\begin{array}{l}\text { "Quando a Renova diz que todos participam, todos expressam sua opinião e } \\
\text { todos tomam uma decisão coletiva, também diz que significa que somos todos } \\
\text { responsáveis. Então, se algo der errado, é responsabilidade de todos. Era a maneira } \\
\text { deles dizerem que, como todos decidem coletivamente, as coisas demoram mais... } \\
\text { durante o protesto em junho, o presidente veio dizer: 'Eu não estou vindo aqui para } \\
\text { resolver nada, mas para dizer-lhe antes que a Fundação não pode tomar uma única } \\
\text { decisão. Requer } 200 \text { pessoas para chegar a um acordo, o que significa que não é } \\
\text { minha responsabilidade como Presidente. Você precisa perseguir os outros também', } \\
\text { e ele acabou de passar o dinheiro para os outros... é um discurso perigoso; não } \\
\text { representa participação, mas descaso de responsabilidade" (Entrevista com uma } \\
\text { ativista feminina do MAB, 2019). }\end{array}$ \\
\hline Lógica jurídica para sua defesa. & Justificação & $\begin{array}{l}\text { "Eu acho que você está certo de que temos narrativas diferentes e visões de } \\
\text { mundo; somos guiados pelo Termo de Ajustamento de Conduta" (Assembleia de } \\
\text { Minas Gerais, 2019). }\end{array}$ \\
\hline
\end{tabular}

Fonte: Elaborado pelo autor.

\section{Resistindo e evitando o parentalismo}

\section{Táticas de autoexclusão}

Para contrariar as diferentes abordagens parentais da Renova, a principal estratégia dos atingidos desde o início foi contornar o espaço de deliberação formal e recorrer, em vez disso, à resistência judicial, civil e mediática. A afirmação central repetidamente exclamada pelos atingidos foi: "Tudo o que alcançamos foi graças à nossa luta e assistência de outros, como os promotores e ONGs. Absolutamente nada nos foi concedido pela boa fé da Renova".

Uma jovem vítima, por exemplo, explicou sua estratégia para lidar com a Renova: "Não somos mais tão afetados por suas manipulações [Renova] durante as reuniões, pois nosso grupo pelo menos não participa mais de seus diálogos e reuniões. O Dr. Guilherme mudou a nossa relação com eles [Renova] para ser jogado nos tribunais".

Ativistas aconselharam também as táticas de autoexclusão às vítimas, conforme explicado pela tensão dialética da "árvore venenosa". Apesar de ter recebido dois assentos no Conselho de Governadores (o único órgão capaz de tomar decisões), uma ativista e promotora estadual apontou o risco e a participação de duas vítimas em circunstâncias caracterizadas por tais assimetrias de poder com respeito a conhecimento, socioeconomia e emoções. Mais importante ainda, os dois alvos serão sempre superados em número pelos quatro representantes da mineração.

\section{Parceria com defensores e ativistas}

Inicialmente resgatamos a importância do jornal dirigido pela vítima Sirene no confronto com o parentalismo da Renova. Criado por uma organização religiosa local, o Sirene é administrado e escrito pelas vítimas, para garantir que suas vozes não sejam esquecidas ou abafadas pela Renova. Uma autoridade religiosa em Mariana declara em uma entrevista:

O terceiro projeto é o jornal Sirene porque queríamos que histórias verdadeiras fossem comunicadas. A mídia editou as histórias à sua maneira. Os objetivos principais aqui são manter a unidade entre os dispersos, levar notícias relatadas pelos próprios atingidos e motivar a memória [...] a Renova teve a ousadia de publicar um jornal próprio num formato e estilo muito semelhantes ao nosso, chama-se Voz da Comunidade [...] também entrevistaram atingidos. 

no Brasil

A maioria dos atingidos do município de Mariana refere-se ao promotor público, Guilherme de Sá Meneghin, como seu 'anjo da guarda'. Em 2017, como resultado da defesa inicial de Meneghin, ganharam o direito de receber assistência técnica para auxiliá-los na compreensão e participação nas deliberações. Os atingidos escolheram a Cáritas, ONG católica de justiça social, para esse papel; antes já eram apoiados pela organização mais de esquerda, radical e antimineração, o MAB. Passaram, então, a estabelecer vínculos com ONGs ativistas estrangeiras.

Essencialmente, as vítimas resistem ao parentalismo, forjando alianças com defensores legais e técnicos, ativistas e representantes da igreja, limitando, portanto, seu envolvimento com o processo deliberativo da Renova. As vítimas também voltaram à ação direta quando necessário. Por exemplo, dezenas delas ocuparam o escritório da Renova em Mariana durante a maior parte de junho de 2019 para protestar contra os atrasos e as táticas de protelação.

Políticos estaduais convocaram audiências públicas de direitos humanos em Belo Horizonte, capital de Minas Gerais. Nesse caso, os políticos que defendem os direitos dos atingidos têm facilitado discursos e intervenções por parte dos residentes locais, da sociedade civil e de atores estatais. Em maio de 2019, o chefe de direitos humanos da Renova aceitou o convite para estar na plateia. $\mathrm{O}$ trecho extraído de sua fala revela as ontologias díspares, entre os dois lados, para o primeiro plano e ajuda a avaliar a lacuna existente na prevenção da reconciliação:

Em termos de saúde, vale lembrar que somos regidos pelo TTAC, principalmente cláusulas 106-112 [...] A Fundação Renova nunca atua unilateralmente, é sempre pautada pelo TTAC e pelas câmaras técnicas criadas dentro do sistema de governança e do comitê interfederativo [...] o movimento social dos atingidos está sendo incorporado pela governança do TTAC do ano passado em conjunto com diferentes promotores públicos [...] no que diz respeito à pesca, seguimos direitos relevantes, como o direito ao trabalho, o direito a soberania alimentar e reparações em geral [...] segundo a Anvisa, peixe é seguro para consumo [vaias, reclamação, público gritando em desacordo por alguns minutos].

Houve interrupção e réplica por parte da deputada estadual Beatriz Cerqueira:

Meu problema aqui é que temos duas narrativas. Por um lado, temos vocês nos contando sobre os conceitos e porque foi criada a Fundação Renova - o conceito de direitos humanos - e, por outro lado, temos a realidade de quem veio aqui para a audiência. Então estou mesmo lutando aqui [...] não há ponto de encontro entre essas duas narrativas. Temos problemas sérios aqui! A narrativa da Fundação Renova fala de aprendizados, governança, desafios e estudos inconclusivos, mas, enquanto isso, as pessoas estão morrendo [gritos da plateia], entendeu? O que você diz sobre a toxicidade da água não se relaciona com a realidade crua [...] como vamos lidar com as futuras audiências da assembleia, por que é completamente antagônico? (Assembleia de Minas Gerais, 2019).

No seu fragmento de discurso, o executivo da Renova expôs a lógica profunda e arraigada da fundação dentro da lógica jurídica do TTAC e nos estudos científicos, presa à esfera formal e sem capacidade para uma discussão informal com a realidade totalmente divergente vivida pelos atingidos. É fundamental enfatizar que, apesar das várias formas de contornar a fundação, não há possibilidade de reparação a todas as vítimas pelos tribunais.

\section{DISCUSSÃO}

Neste artigo, apontamos como o parentalismo e suas tensões subjacentes moldam a dinâmica deliberativa. Isso envolve abordar uma lacuna na literatura sobre como as 'crianças', ou partes interessadas, reagem às estratégias parentais de PCSR e como os 'pais', ou atores organizacionais, justificam moralmente suas ações em face da resistência e dissidência.

Assim, este estudo preenche as lacunas apontadas por Gond et al. (2016) e Etchanchu e Djelic (2019) sobre como formas menos visíveis de poder e justificação interagem de maneira que ajudam a moldar a dinâmica deliberativa em MSIs.

Esta análise de caso traz para o primeiro plano as tensões dialéticas e o impacto do PCSR parentalista deliberativo sobre as vítimas de abusos de direitos humanos que buscam reparação corporativa. A principal contribuição deste estudo para a literatura de PCSR é a apresentação de um modelo de processo de PCSR parentalista com uma dinâmica de resistência das partes interessadas em um nível micropolítico. A Figura 2 captura essas dinâmicas e processos de nível micropolítico. 
Figura 2

Modelo de processo dialético de resistência e subversão dos stakeholders ao PCSR parentalista

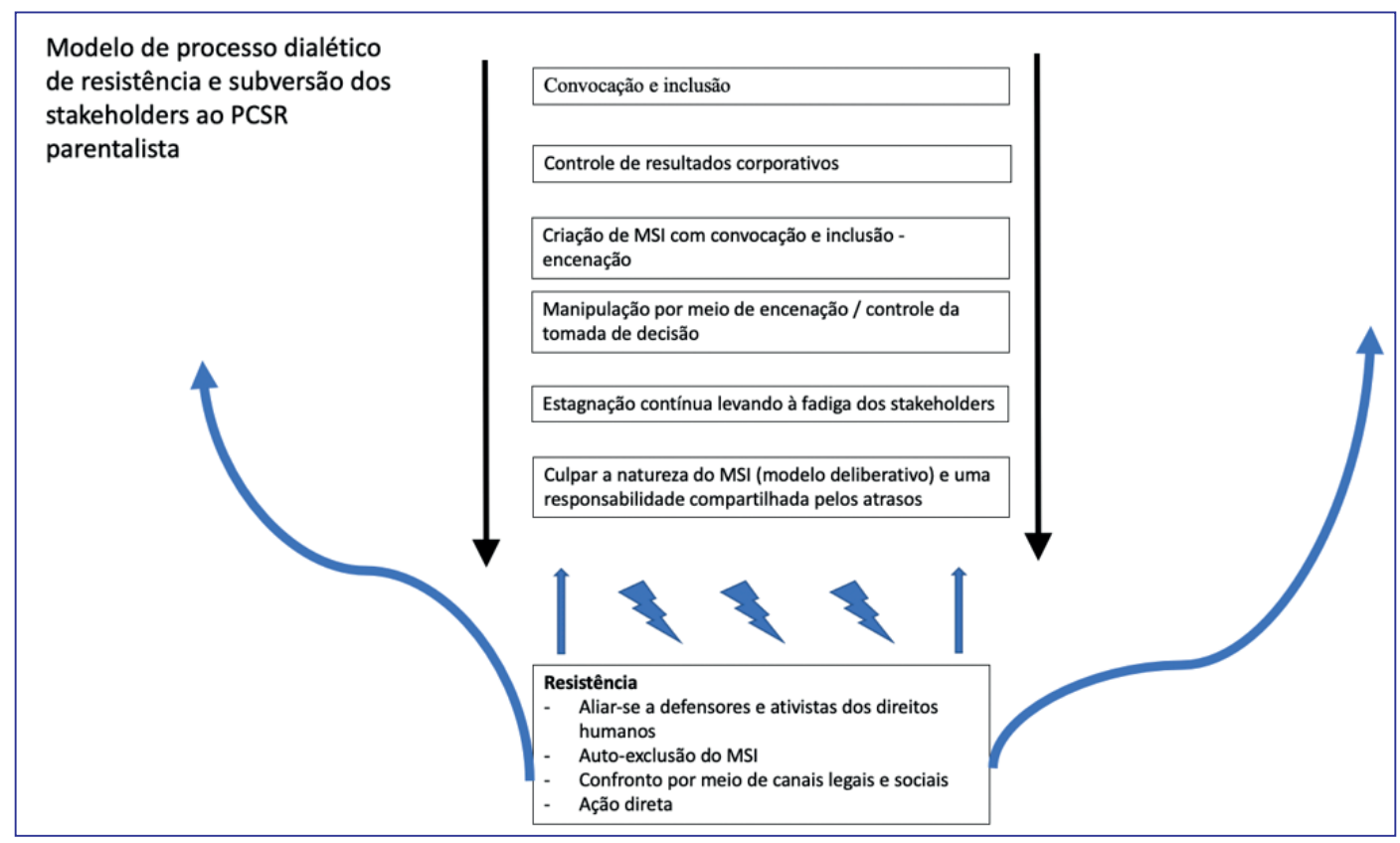

Fonte: Elaborada pelo autor.

Com base no PCSR e parentalismo, propomos, neste estudo, as estratégias de encenação, paralisação, fadiga das partes interessadas, resistência das partes interessadas e justificativas morais corporativas em resposta à dissidência. Assim, há dois temas relacionados - estagnação e fadiga das partes interessadas - que retratam a mecânica de como as empresas podem buscar legitimar seus atos de irresponsabilidade por meio das MSIs (Moog et al., 2015).

Entendemos que a preparação permite que as MSIs e as organizações paralisem suas ações, levando ao esgotamento das partes interessadas, que conseguem resistir por meio da autoexclusão do PCSR e de parcerias com defensores de direitos, o que pode auxiliar na neutralização dos elementos significativos da encenação. Nesse caso, adicionamos dinamismo ao parentalismo, uma vez que este estudo se aprofundou na mecânica de suas dimensões de poder e justificação (Etchanchu \& Djelic, 2019).

Os dados aludem a uma conexão entre os ajustes dos arranjos de governança das MSIs e a 'encenação' de uma deliberação justa, o que permite que as organizações se envolvam em táticas de paralisação. Se a fundação tivesse optado por evitar uma abordagem maquiavélica na preparação de seu MSG, mantendo o controle da tomada de decisões, teria lutado continuamente para dar às vítimas uma confusão durante anos, como atualmente continua a fazer, mesmo cinco anos após o desastre. Isso pode explicar por que são apresentados mais processos relacionados ao estágio do que aqueles vinculados ao bloqueio. Entendemos que as manobras de encenação, como o estabelecimento de arranjos do tipo "árvore venenosa", são um pré-requisito para protelamentos e atrasos por poderosos atores parentalistas dentro de PCSRs e MSIs.

Por um lado, a legitimidade democrática do input (Mena \& Palazzo, 2012) da Fundação Renova pareceria inclusiva, consensualmente orientada e transparente. Por outro, sua justiça processual pode ser facilmente posta em questão diante do armamento do tempo e da paralisação e do fato de que não foi projetado em consulta com os atingidos e não lhes confere nenhum poder real de tomada de decisão. A Fundação Renova, de forma flagrante, fica aquém de sua legitimidade de produção (Mena \& Palazzo, 2012) sob a perspectiva das vítimas e de seus defensores.

Além disso, o caso aponta para o tempo como um recurso estratégico que pode ser explorado pelo ator parental para exercer seu poder e obter submissão das partes interessadas, das 'crianças', por meio do cansaço e de uma sensação de desesperança. 

no Brasil

Aqui, podemos observar que as organizações parentais não apresentam dificuldade em reabastecer seu quadro de funcionários. Não à toa o padre, por meio de uma analogia com o nome da fundação, ironiza apontando que a única coisa que renovam é o quadro. Já as demais partes envolvidas não têm essa capacidade de renovar suas energias. Além disso, os lamentos nas conversas mais recentes com as vítimas ressaltam o impacto emocional do tempo, protelação e atrasos.

A segunda maior contribuição deste artigo é postular que as partes interessadas resistam ao parentalismo corporativo (e PCSR) em MSIs (ver Figura 2), contornando e/ou confrontando a institucionalidade da MSI por meio da autoexclusão; optando por canais legais, em alianças com defensores dos direitos humanos legais, estatais e da sociedade civil; bem como em ações diretas e se envolvendo em comunicações regulares que expressem suas queixas contra as MSIs.

No entanto, devemos estipular que a resistência das partes interessadas ao PCSR não pode ser totalmente efetiva quando a MSI em questão está legalmente mandatada, como é o caso da Fundação Renova. As vítimas têm conseguido, em grande parte, contornar as instâncias deliberativas e participativas com a fundação e obter uma indenização mais generosa nos tribunais em decorrência da perícia legal do Ministério Público. Conseguiram também afetar a imagem da Renova por meio de outros atos de resistência. Isso, no entanto, não eliminou as táticas de paralisação contínuas da fundação, que acabam desgastando e exaurindo as vítimas. No geral, ainda é verdade que os espaços da MSI restringem a deliberação política real, visto que vozes minoritárias e radicais frequentemente se (auto) excluem (Maher, 2019).

Em suma, argumentamos que a legalidade e os arranjos legais que regem MSIs e PCSR irão determinar a extensão e o nível de resistência efetiva das partes interessadas ao parentalismo.

As corporações podem se opor, afirmando não haver outra alternativa viável para remediar os impactos sobre os direitos humanos que não seja uma abordagem parental MSG, o que corrobora a afirmação de Etchanchu e Djelic (2019) de que a convocação meramente consultiva é justificada por meio do objetivo e conhecimento superior e eficiência dos 'pais/EMNs'. As empresas também podem ameaçar as partes interessadas com mais atrasos, caso desejem obter uma influência significativa na tomada de decisões da MSI.

A análise do caso também revela como as corporações justificam atrasos ao predizer que a democracia deliberativa e a busca pela construção de consenso constituem um processo lento, muitas vezes burocrático, mas legítimo, que não permite decisões e soluções rápidas por um único ator. Essa é uma resposta particularmente insensível, na medida em que lida com queixas relacionadas a atos corporativos de irresponsabilidade para os quais a fundação foi criada. Essencialmente, organizações parentais, como a Renova, podem se proteger da culpa desviando a responsabilidade para as próprias vítimas e enfatizando que a responsabilidade é compartilhada entre todas as partes interessadas. As organizações também podem apoiar-se em discursos jurídico-racionais para pleitear legitimidade, como o fez a Renova ao conceber suas ações para sua governança e operacionalização baseada em uma lei (TTAC). Essas estratégias de interação dinâmica indireta ajudam a desmascarar a dominação (Banerjee, 2018). O caso da Renova é exemplo de diálogo que não foi isento de coerção interna ou externa (mascarado por dinâmicas de influência por encenação, protelação e esgotamento dos stakeholders) nem capaz de lançar ações coletivas por meio do consenso (Habermas, 2000).

A análise da Fundação Renova também aponta para os limites da perspectiva agnóstica, cada vez mais popular, na democracia deliberativa (Arenas et al., 2020; Fougère \& Solitander, 2020). Entendemos que, sem um acordo final para a restituição das perdas materiais e imateriais sofridas pelas vítimas de prevaricação corporativa, o pluralismo agnóstico tem pouco a oferecer. Aprender a coexistir em desacordo com atores com diferentes perspectivas e realidades não mitiga o sofrimento das vítimas pela prevaricação corporativa. No caso da Renova, a resistência de 'linha de frente' dos atingidos incluiu atos de 'sentimento anticonsenso' (Mouffe, 2000), conforme relatado anteriormente na discussão sobre a resistência ao parentalismo PCSR.

As empresas podem, como demonstrado por este estudo de caso, usar perversamente - em um sentido maquiavélico - MSIs independentes projetadas para fornecer reparação como forma de se esquivarem das responsabilidades associadas aos seus deveres em relação ao cuidado e respeito aos direitos humanos de suas vítimas. Com base neste artigo, concordamos com Thompson (2017) que a solução ideal para a remediação corporativa da perspectiva da vítima seria capacitá-la para determinar seus próprios resultados, conforme evidenciado no caso empírico de Reinecke e Donaghey (2021). 

no Brasil

Além disso, os culpados corporativos devem dar um passo atrás no processo de reparação e permitir que um processo de múltiplos stakeholders seja submetido a uma reparação justa e eficiente, tendo facilitação de representantes do judiciário. Consequentemente, isso implicaria o estabelecimento de uma futura 'fundação MSG independente', na qual o poder de tomada de decisão cabe a vítimas, especialistas e atores judiciais e não às corporações responsáveis por causar danos.

\section{Agenda de pesquisa}

Estudos futuros devem examinar em quais condições a resistência ao PCSR parentalista é mais ou menos bem sucedida. PCSR, soluções corporativas e estudiosos de negócios e direitos humanos devem considerar ainda as relações de dependência entre a empresa perpetradora e a comunidade, particularmente no contexto do colonialismo interno. A dependência do sustento da vítima em relação às empresas, em virtude dos empregos, significa que a economia local e a filantropia podem substituir qualquer diálogo restaurador bem-intencionado, tornando-o fútil.

A exploração adicional e o desenvolvimento da paralisação como um conceito em outros PCSRs e contextos deliberativos devem fornecer um caminho frutífero em pesquisas futuras para determinar o quão prevalente é essa tática em outros contextos, como aqueles que envolvem trabalhadores e cadeias de suprimentos. Poderíamos então aprender mais sobre como o papel da gestão do tempo e da governança em geral é aproveitado pelas organizações dentro de espaços deliberativos para manter o poder e controlar os resultados finais. Pesquisas futuras podem avançar nosso entendimento teórico de como a resistência ao PCSR afeta as táticas de encenação e paralisação de maneira diferente, bem como examinar o protagonismo dos atores estatais na criação e operação de MSIs, especialmente no contexto de prevaricação e remediação corporativa.

\section{CONCLUSÃO}

Neste artigo, examinamos as estratégias interacionais dinâmicas, indiretas e menos visíveis, de uma perspectiva de PCSR relacionada ao parentalismo, e delineamos as principais estratégias de resistência das partes interessadas e/ou vítimas ao parentalismo nos MSIs.

Ao examinar o caso da Fundação Renova, dissecamos como funciona um modelo mais dinâmico de parentalismo deliberativo, por meio de 12 tensões dialéticas em ação, como o parentalismo deliberativo.

Este estudo também revelou que as 'crianças' (partes interessadas) podem contestar e confrontar seus 'pais' autoexcluindo-se do MSI para estabelecer alianças com outras ONGs e organizações estatais, bem como com atores que podem ajudar a dar voz aos seus direitos fora dos espaços formais de MSI, como por meio de canais legais e movimentos sociais. Apesar de a resistência ao PCSR, no caso desta pesquisa, ter ajudado a expor e - até certo ponto - descarrilar as práticas maquiavélicas da fundação, não foi, ainda, suficiente à obtenção do nível desejado de justiça às vítimas. Entretanto, é digno de nota que a resistência das partes interessadas neste contexto dependia do grau de legitimidade legal da MSI.

As organizações parentais justificam seu comportamento e os resultados das deliberações das partes interessadas ancorando sua defesa em um discurso legal e racional e atribuindo a culpa à própria democracia deliberativa. Em outras palavras, sua natureza burocrática torna cada decisão e resultado uma responsabilidade compartilhada por todas as partes interessadas. Resumindo, o caso mostra como as organizações MSI podem desviar as acusações de práticas ineficientes para as partes interessadas.

A conclusão é que as MSIs centradas na deliberação não são adequadas em casos com inúmeras vítimas que requerem reparação corporativa e, ainda, que as empresas infratoras não devem decidir sobre a forma como as vítimas receberão reparação. Em vez disso, as próprias vítimas, juntamente com as diversas partes interessadas, devem ser capazes de decidir os resultados de tais processos. Em termos teóricos, isso levanta questões sobre a validade das perspectivas democráticas agnósticas no tratamento de casos de remediação corporativa de abusos de direitos humanos, enquanto as vítimas buscam assentamentos. 

no Brasil

Por fim, o caso da Fundação Renova serve como exemplo de organização, de acordo com o parentalismo, colocando um foco enviesado em tornar o processo ou lado de entrada das MSIs inclusivos e centrados no diálogo, enquanto não consegue fazer o mesmo na outra extremidade com resultados ou produtos.

\section{AGRADECIMENTOS}

Dedico este artigo aos atingidos pelo rompimento da barragem Fundão. Não teria sido possível escrevê-lo sem o tempo que me dedicaram com inúmeras e longas conversas (especialmente Lucimar, Mirella, Marino e Maria). Agradeço a vocês por terem me ensinado a ser forte e lutar. Também à Cáritas por sua pronta disposição em todas as entrevistas. À Fundação Renova pelas revistas concedidas durante o ano de 2019.

Profundos agradecimentos a Hélio Arthur Irigaray e a Fabricio Stocker pela ajuda com a tradução e preparação deste artigo em português. A Aida Ancleto, Adriana Bravin, Alberto Fonseca, Yuna Fontoura e Dulce Perreira pelas boas discussões em torno do artigo. 


\section{REFERÊNCIAS}

Alamgir, F., \& Banerjee, S. B. (2019). Contested compliance regimes in global production networks: Insights from the Bangladesh garment industry. Human Relations, 72(2), 272-297. Recuperado de https:// doi.org/10.1177/0018726718760150

Arenas, D., Albareda, L., \& Goodman, J. (2020, abril). Contestation in multi-stakeholder initiatives: Enhancing the democratic quality of transnational governance. Business Ethics Quarterly, 30(2), 169-199. Recuperado de https://doi.org/10.1017/beq.2019.29

Assembleia de Minas Gerais. (2019, agosto 17). 26/08/2019 09:30 Comissão de Direitos Humanos. Recuperado de https://www.youtube. com/watch?v=dnwHWRTGFEc

Bäckstrand, K. (2010). From rhetoric to practice: The legitimacy of global public-private partnerships for sustainable development. In M. Bexell, \& U. Mörth (Eds.), Democracy and public-private partnerships in global governance (pp. 145-166). London, UK: Palgrave Macmillan.

Banerjee, S. B. (2018). Transnational power and translocal governance: The politics of corporate responsibility. Human Relations, 71(6), 796821. Recuperado de https://doi.org/10.1177/0018726717726586

Brand, T., Blok, V., \& Verweij, M., (2020, janeiro). Stakeholder dialogue as agonistic deliberation: Exploring the role of conflict and self-interest in business-NGO interaction. Business Ethics Quarterly, 30(1), 3-30. Recuperado de https://doi.org/10.1017/beq.2019.21

CAC UFMG. (2019, março 15). III UFMG Debate - Para além do rompimento: Lições de Mariana. Recuperado de https://www. youtube.com/watch?v=DE2aM1V7d5A

Dawkins, C. (2015, janeiro). Agonistic pluralism and stakeholder engagement. Business Ethics Quarterly, 25(1), 1-28. Recuperado de https://doi.org/10.1017/beq.2015.2

Dubois, A., \& Gadde, L. E. (2002). Systematic combining: An abductive approach to case research. Journal of Business Research, 55(7), 553560. Recuperado de https://doi.org/10.1016/S0148-2963(00)00195-8

Ehrnström-Fuentes, M. (2016, maio). Delinking legitimacies: A pluriversal perspective on political CSR. Journal of Management Studies, 53(3), 433-462. Recuperado de https://doi.org/10.1111/ joms. 12173

Etchanchu, H., \& Djelic, M. L. (2019). Old wine in new bottles? Parentalism, power, and its legitimacy in business-society relations. Journal of Business Ethics, 160(4), 893-911. Recuperado de https:// doi.org/10.1007/s10551-018-3928-9

Fougère, M., \& Solitander, N. (2020). Dissent in consensusland: An agonistic problematization of multi-stakeholder governance. Journal of Business Ethics, 164, 683-699. Recuperado de https://doi. org/10.1007/s10551-019-04398-z

Fundação Renova. (2010). Website. Recuperado de www. fundacaorenova.org

Gond, J. P., Barin Cruz, L., Raufflet, E., \& Charron, M. (2016, maio). To frack or not to frack? The interaction of justification and power in a sustainability controversy. Journal of Management Studies, 53(3), 330-363. Recuperado de https://doi.org/10.1111/joms.12166
Habermas, J. (1998). The inclusion of the other: Studies in political theory. In C. C., \& P. De Greiff (Eds.), Studies in contemporary german social thought. Cambridge, UK: MIT Press.

Habermas, J. (2000). On the pragmatics of communication. Cambridge, UK: MIT Press.

Maher, R. (2019). Squeezing psychological freedom in corporatecommunity engagement. Journal of Business Ethics, 160(4), 10471066. Recuperado de https://doi.org/10.1007/s10551-018-3898-y

Mena, S., \& Palazzo, G. (2012, julho). Input and output legitimacy of multistakeholder initiatives. Business Ethics Quarterly, 22(3), 527-556. Recuperado de https://doi.org/10.5840/beq201222333

Miranda, M. G., Friede, R., Rodrigues, A. C., \& Almeida, D. S. (2017). Cadê a minha cidade, ou o impacto da tragédia da Samarco na vida dos moradores de Bento Rodrigues. Interações (Campo Grande), 18(2), 3-12. Recuperado de https://doi.org/10.20435/inter.v18i2.1410

Moog, S., Spicer, A., \& Böhm, S. (2015). The politics of multistakeholder initiatives: The crisis of the Forest Stewardship Council. Journal of Business Ethics, 128(3), 469-493. Recuperado de https:// doi.org/10.1007/s10551-013-2033-3

Mouffe, C. (2000). Deliberative democracy or agonistic pluralism (Reihe Politikwissenschaft / Institut für Höhere Studien, Abt. Politikwissenschaft, 72). Wien, Austria: Institut für Höhere Studien: Institut für Höhere Studien (IHS).

Reinecke, J., \& Donaghey, J. (2021, março). Political CSR at the coalface-The roles and contradictions of multinational corporations in developing workplace dialogue. Journal of Management Studies, 58(2), 457-486. Recuperado de https://doi.org/10.1111/joms.12585

Reuters. (2018, janeiro 30). Vale prevê mais dois anos para reparar danos do desastre da Samarco, diz presidente. G1. Recuperado de https://g1.globo.com/economia/noticia/vale-preve-mais-dois-anospara-reparar-danos-do-desastre-da-samarco-diz-presidente.ghtml

Sabadoz, C., \& Singer, A. (2017). Talk ain't cheap: Political CSR and the challenges of corporate deliberation. Business Ethics Quarterly, 27(2), 183-211.

Scherer, A. G., \& Palazzo, G. (2007). Toward a political conception of corporate responsibility: Business and society seen from a Habermasian perspective. Academy of management review, 32(4), 1096-1120. Recuperado de https://doi.org/10.2307/20159358

Scherer, A. G., \& Palazzo, G. (2011, junho). The new political role of business in a globalized world: A review of a new perspective on CSR and its implications for the firm, governance, and democracy. Journal of management studies, 48(4), 899-931. Recuperado de https://doi. org/10.1111/j.1467-6486.2010.00950.x

Schormair, M. J., \& Gerlach, L. M. (2020). Corporate remediation of human rights violations: A restorative justice framework. Journal of Business Ethics, 167, 475-493. Recuperado de https://doi.org/10.1007/ s10551-019-04147-2

Thompson, B. (2017, janeiro). Determining criteria to evaluate outcomes of businesses' provision of remedy: Applying a human 

no Brasil

rights-based approach. Business and Human Rights Journal, 2(1), 55-85. Recuperado de https://doi.org/10.1017/bhj.2016.30

Vogel, D. (2010). The private regulation of global corporate conduct. Achievements and limitations. Business and Society, 49(1), 68-87. Recuperado de https://doi.org/10.1177/0007650309343407
Zhouri, A., Oliveira, R., Zucarelli, M., \& Vasconcelos, M. (2018). O desastre no Rio Doce: entre as políticas de reparação e a gestão das afetações. Mineração, violências e resistências: um campo aberto à produção do conhecimento no Brasil (pp. 28-64). Marabá, PA: Editorial iGuana. 